\section{Treatment of unusual rectal foreign body using a Foley catheter}

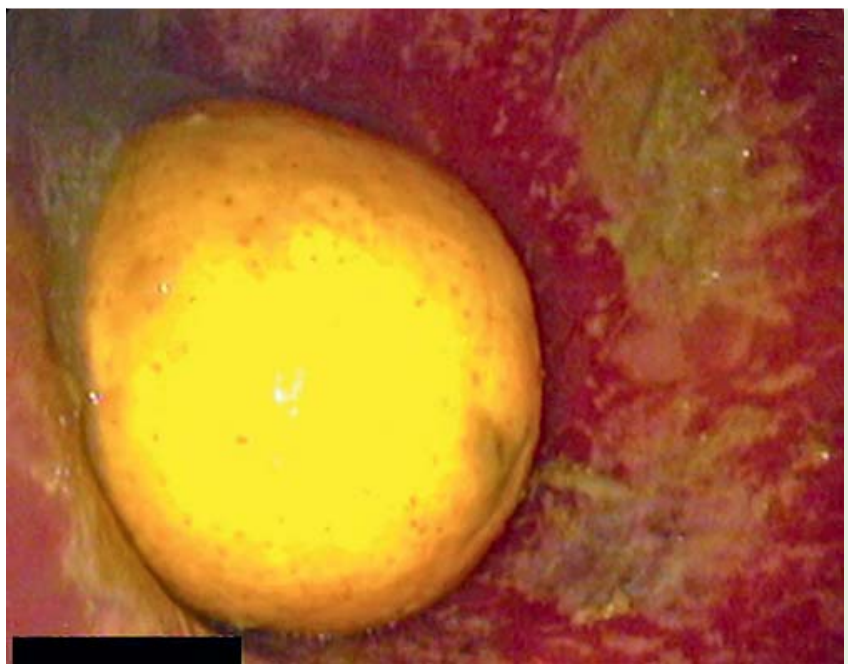

Fig. 1 Endoscopic view of the mandarin in the rectum.
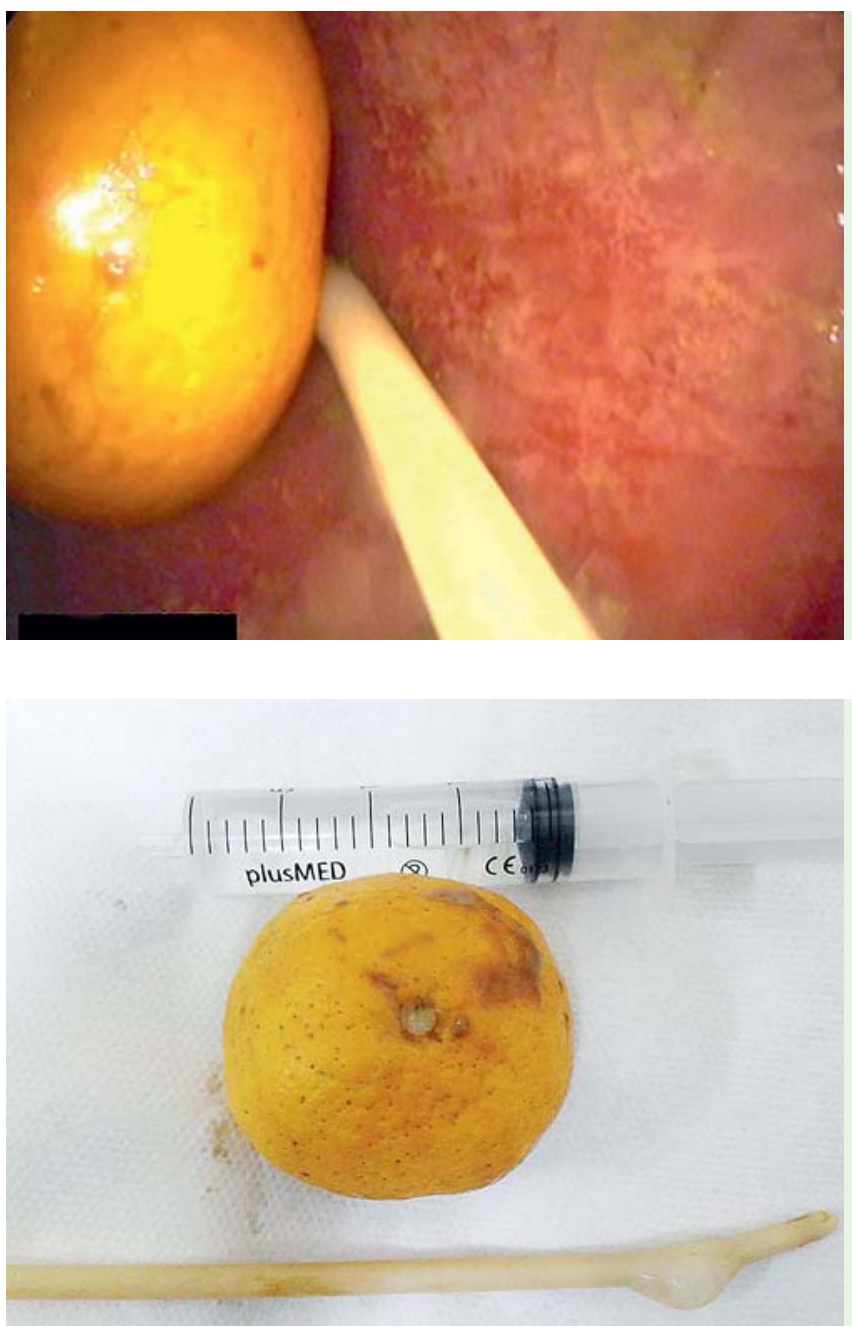

A 70-year-old man presented to our emergency department with a history of abdominal pain and bloating and lack of defecation for 3 days. A round, hard foreign body with a smooth surface was palpated on digital rectal examination. The man admitted having introduced a mandarin into the rectum 4 days previously. An attempt at manual extraction of the foreign body was unsuccessful. Endoscopic examination of the rectum showed that a round, orange-colored mandarin was almost completely obstructing the lumen, and did not allow the colonoscope (Pentax EC-380LKp, Tokyo, Japan) to pass to proximally beyond it ( $\mathbf{F i g} \mathbf{1}$ ). Grasping the mandarin with a $50-\mathrm{mm}$ polypectomy snare (Endo-Technik, Solingen, Germany) failed because of the mandarin's round and smooth surface. A 14-French Foley catheter (PlusMed; Sisco Latex PVT, Chennai, India) was inserted and passed proximally to the mandarin under colonoscopic observation ( Fig. 2). The balloon of the catheter was inflated with $20 \mathrm{~mL}$ water and pulled gently. In this way the mandarin was fully extracted without complication ( $\bullet$ Fig.3). After the extraction, control endoscopic examination revealed only mild superficial laceration of the rectal mucosa. The patient was observed for a few hours after the procedure and discharged from the hospital on the same day.

Most rectal foreign bodies have been inserted for sexual stimulation and are generally blunt, round, and have a smooth surface. Repetitive insertion of gradually larger objects makes these objects more difficult to remove [1]. Grasping round, large, smooth-surfaced objects is difficult with standard endoscopic devices $[2,3]$. In such cases, using a Foley catheter in the treatment of rectal foreign bodies may allow a major surgical procedure to be avoided [4].

Endoscopy_UCTN_Code_TTT_1AQ_2AH

Competing interests: None

\section{Abdurrahim Sayılır ${ }^{1}$, Ibrahim Nadir Düzgün², Bülent Güvendi ${ }^{2}$}

${ }^{1}$ Department of Gastroenterology, Prof. Dr. A. Illhan Özdemir Giresun State Hospital, Giresun, Turkey

2 Department of General Surgery, Prof. Dr. A. IIlhan Özdemir Giresun State Hospital, Giresun, Turkey 


\section{References}

1 Fry RD. Anorectal trauma and foreign bodies. Surg Clin North Am 1994; 74: 1491 1505

2 Billi P, Bassi M, Ferrara F et al. Endoscopic removal of a large rectal foreign body using a large balloon dilator: report of a case and description of the technique. Endoscopy 2010; 42: E238

3 van der Wouden EJ, Westerveld BD. Extraction of a rectal foreign body using a custom-made giant snare. Endoscopy 2010; 42: E122

4 Humes $D$, Lobo DN. Removal of a rectal foreign body by using a Foley catheter passed through a rigid sigmoidoscope. Gastrointest Endosc 2005; 62: 610
Bibliography

DOI http://dx.doi.org/

10.1055/s-0034-1365109

Endoscopy 2014; 46: E182-E183

(c) Georg Thieme Verlag KG

Stuttgart · New York

ISSN 0013-726X

\section{Corresponding author}

Abdurrahim Sayılır, MD

Department of Gastroenterology

Prof. Dr. A. Ilhan Ozdemir Giresun State Hospital

Teyyaredüzü Mah. Atatürk Bulvarı No: 323

Giresun

Turkey

Fax: +90-454-2155146

drabdurrahim@gmail.com 